\title{
Portal Vein Aneurysm Mimicking a Liver Nodule
}

\author{
Luís Maia $^{\mathrm{a}}$ Fernando Manuel Castro-Poças ${ }^{\mathrm{b}}$ Isabel Pedroto ${ }^{\mathrm{a}}$ \\ Departments of ${ }^{\mathrm{a}}$ Gastroenterology and ${ }^{\mathrm{b}} \mathrm{Ultrasound}$ and Gastroenterology, Centro Hospitalar Universitário \\ do Porto, Instituto de Ciências Biomédicas Abel Salazar, Porto, Portugal
}

Keywords

Portal vein · Aneurysm · Liver mass

\section{Aneurisma da Veia Porta Simulando um Nódulo Hepático}

\section{Palavras Chave}

Veia porta · Aneurisma · Nódulo hepático

A 67-year-old woman with diabetes mellitus and arterial hypertension was referred to our outpatient clinic to further clarify a $3-\mathrm{cm}$ nodule of the caudate lobe in an apparently noncirrhotic liver detected on abdominal ultrasound which was performed due to abdominal bloating. She denied alcohol or drug use, traveling, contact with animals, previous abdominal disease, surgery or trauma and family history of hepatic disease, and had not been on any medication except metformin, olmesartan, and amlodipine. Physical examination and laboratory tests, including liver chemistries, were unremarkable.

In order to reevaluate the nodule and due to its better availability, an abdominal Doppler ultrasound was performed in first instance, revealing a normal liver and a $38 \times 28 \mathrm{~mm}$ nodular hypoechoic lesion with posterior acoustic enhancement located between the left lobe of the liver and the pancreatic head, apparently adjacent to the portal vein trunk, with positive Doppler sign (Fig. 1).

At this point, the lesion was considered to be of vascular nature, and as the patient refused magnetic resonance imaging (MRI) due to claustrophobia, an abdominal computed tomography (CT) scan was performed, describing a normal liver and a portal vein trunk aneurysm with a 35-mm diameter, without thrombosis or compression of adjacent structures (Fig. 2). After multidisciplinary discussion, conservative management with clinical and Doppler ultrasound surveillance of complications such as thrombosis or compression of structures was proposed to the patient, and no such events occurred during 1 year of follow-up.

Portal vein aneurysms, defined as a portal vein diameter exceeding $19 \mathrm{~mm}$ in cirrhotic patients and $15 \mathrm{~mm}$ in noncirrhotic ones, are extremely rare, with about 200 cases published, most being extrahepatic [1]. A proportion is believed to be congenital due to incomplete regression of the right primitive distal vitelline vein, explaining its presence in patients with no history of cirrhosis, pancreatitis, abdominal trauma or malignancy [2]. Half of the patients present with nonspecific abdominal pain and less than $10 \%$ have a serious complication, with spontaneous rupture being unfrequently reported [1]. Abdominal Doppler ultrasound and especially CT and MRI are helpful for the diagnosis, evaluation and determining of the exact location of the aneurysm.

\section{KARGER}

E-Mail karger@karger.com www.karger.com/pjg
C 2017 Sociedade Portuguesa de Gastrenterologia Published by S. Karger AG, Basel Karcer Open access

This article is licensed under the Creative Commons AttributionNonCommercial-NoDerivatives 4.0 International License (CC BYNC-ND) (http://www.karger.com/Services/OpenAccessLicense) Usage and distribution for commercial purposes as well as any distribution of modified material requires written permission.
Dr. Luís Maia

Department of Gastroenterology, Centro Hospitalar Universitário do Porto Largo Prof. Abel Salazar PT-4099-001 Porto (Portugal)

E-Mail luismaia.gastro@gmail.com 

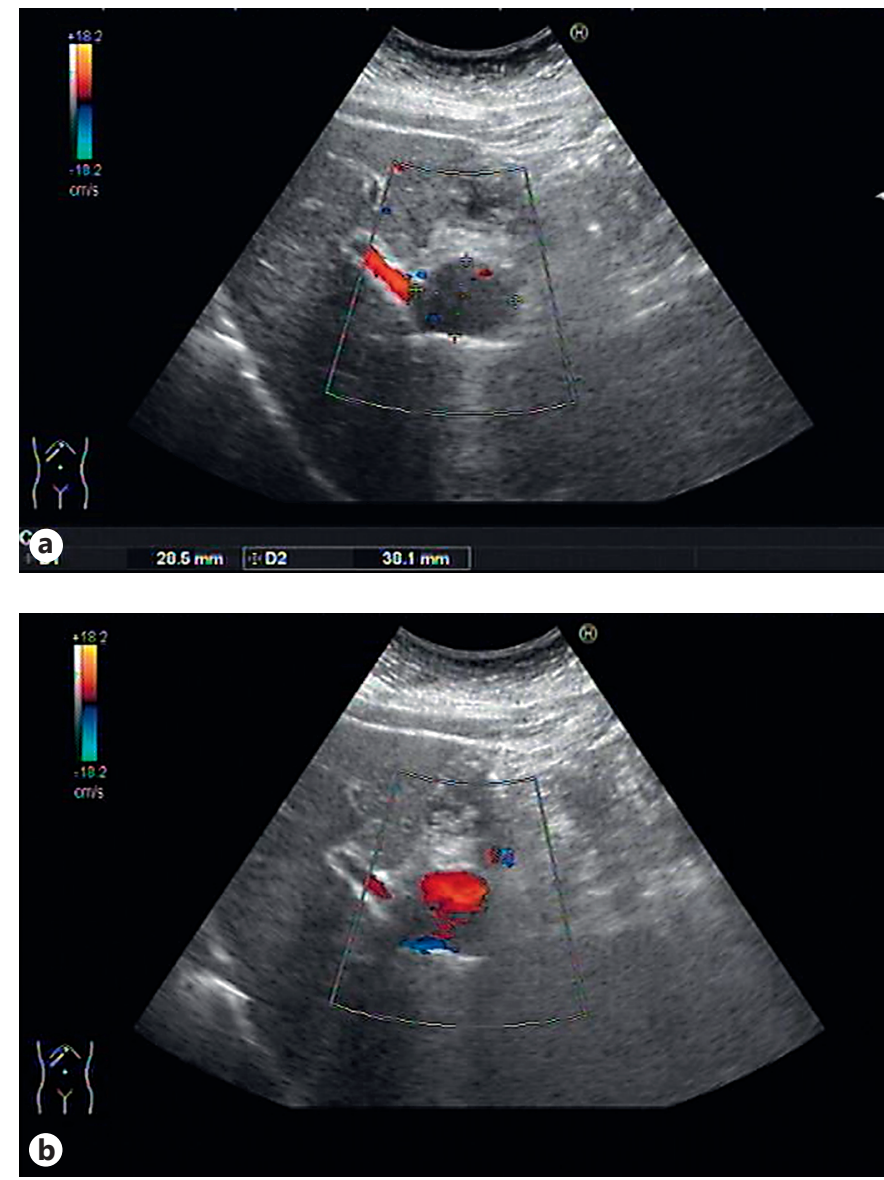

Fig. 1. Abdominal Doppler ultrasound showing a nodular lesion adjacent to the portal vein trunk (a) with positive Doppler sign (b).

The management of portal vein aneurysms is not well established. Invasive therapies such as surgery (aneurysmorrhaphy, aneurysmectomy, shunt or liver transplantation) or endovascular techniques are only warranted in case of complications or important symptoms due to its high postprocedure mortality $[1,3]$. In asymptomatic patients, especially those without portal hypertension, conservative management seems to be the best option.

\section{Statement of Ethics}

This study did not require informed consent nor review/approval by the appropriate ethics committee.

\section{Disclosure Statement}

The authors have no conflict of interest nor funding sources to declare.
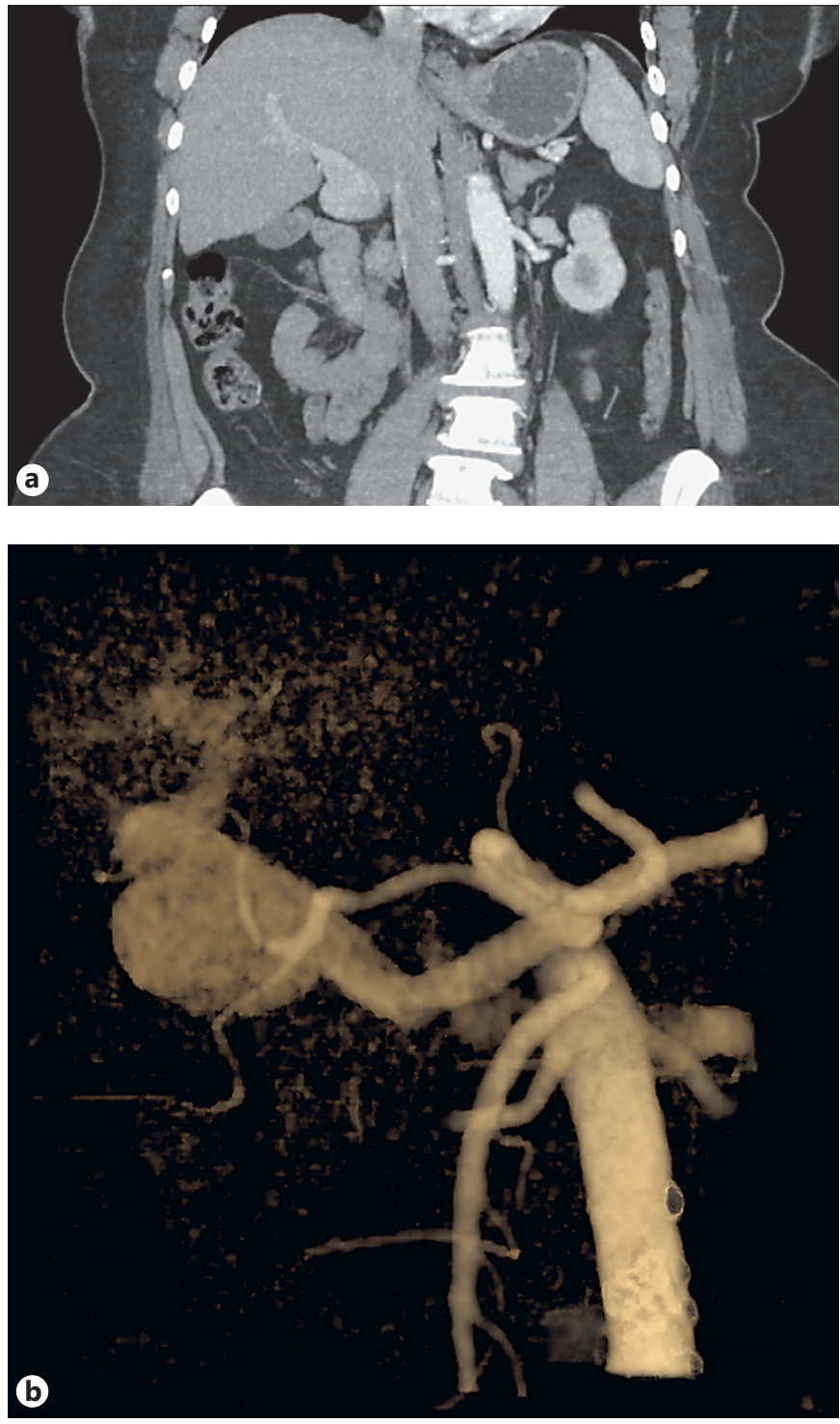

Fig. 2. Contrast-enhanced abdominal CT revealing a portal vein trunk aneurysm without complications in the coronal plane (a) and 3-dimensional reconstruction (b).

References

1 Laurenzi A, Ettorre GM, Lionetti R, Meniconi RL, Colasanti M, Vennarecci G: Portal vein aneurysm: what to know. Dig Liver Dis 2015; 47:918-923.

2 Gallego C, Velasco M, Marcuello P, Tejedor D, De Campo L, Friera A: Congenital and acquired anomalies of the portal venous system. Radiographics 2002;22:141-159.

3 Shukla PA, Kolber MK, Kumar A, Patel RI: Percutaneous embolization of an intrahepatic portal vein aneurysm. J Vasc Interv Radiol 2016;27:1747-1749.

Maia/Castro-Poças/Pedroto 